\title{
FRAUDES À COTA DE GÊNERO NA PERSPECTIVA DO DIREITO ELEITORAL SANCIONADOR
}

\author{
Gender Quota Fraud from the Perspective of Electoral Sanctioning Law
}

\section{Amanda Guimarães da Cunha Luiz Magno Pinto Bastos Junior}

Resumo: Para fomentar a participação feminina na política, o art. 10, \ 3ำ, da Lei 9.504/97 impõe aos partidos políticos o dever de lançarem um mínimo de $30 \%$ de candidatas nos pleitos eleitorais. Entretanto, esse avanço na promoção formal da igualdade de gênero não foi acompanhado por mecanismos que coibissem o uso de "candidatas laranja", nem de previsão legal que estabelecesse uma punição diante de seu descumprimento. Tal lacuna foi preenchida jurisprudencialmente, de forma que tais situações passaram a ser apuradas como fraudes às cotas de gênero ou como abuso de poder (político). Não obstante, a questão mais problemática diz respeito ao alcance da punição: se limitada àquelas e àqueles diretamente envolvidos no ilícito, aos vinculados ao partido político no qual ocorreu a fraude ou se deve atingir toda a coligação. A questão tramitou pelos tribunais regionais eleitorais do País, nos quais se formou o entendimento de que toda coligação deveria ser punida, tese acatada pelo Tribunal Superior Eleitoral (TSE) no julgamento do Recurso Especial Eleitoral $n^{-}$193-92/PI. Com isso, estabeleceu-se uma fórmula de responsabilização objetiva, sem análises de elementos subjetivos para caracterização das condutas, tampouco com aferição do nexo de causalidade, o que permitiu inclusive que candidatas legitimamente eleitas fossem cassadas. O objetivo deste trabalho consistiu em analisar se a fórmula adotada e o alcance das punições são compatíveis com a garantia constitucional do devido processo legal, tendo em vista que se está diante do exercício do jus puniendi do Estado, qualificado como direito eleitoral sancionador. Chegou-se à conclusão de que a responsabilização pelo cometimento dessas fraudes não pode ultrapassar àquelas e àqueles que tenham concorrido diretamente para a perpetração do ilícito, podendo atingir excepcionalmente os filiados a partido político que tenham institucionalmente agido no sentido de fraudar a política afirmativa. Sustentam os autores que a solução fixada pelo TSE importa em malversação dos pilares democráticos e constitucionais e podem levar à autofagia da própria política afirmativa.
Palavras-chave: Cota de gênero. Candidaturas laranja. Responsabilização objetiva. Direito eleitoral sancionador.

Abstract: To encourage female participation in politics, art. 10, \3o of Law 9504/97 imposes that political parties must present a minimum of $30 \%$ of women candidates in the elections. However, this advance to promote gender equality was not accompanied by monitoring mechanisms to prevent parties from bending the rule nor legal provision to punish non-compliance. Jurisprudence has worked to fill this gap, and deviant practices - such as appointing candidates to comply with the quota who were not actually running, the so-called "non-viable candidates" - started to be investigated as fraud or abuse of power. Nevertheless, the most problematic issue concerns the scope of the punishment, i.e., whether restricted to those directly involved, the political party, or the electoral coalition. Brazil's regional electoral courts have debated this issue, and the dominant understanding is that the whole coalition should be punished. The Superior Electoral Court (TSE) accepted this theory in the judgment of RESPE 19392/PI. Thus, an objective liability formula was established, without analyzing subjective elements to characterize the conduct and with no assessment of the causal link, which has led to the removal of legitimately elected female candidates. This study examines whether the formula adopted and the scope of the punishments were compatible with the due process, considering the exercise of the state's jus puniendi, which is qualified as an electoral sanctioning right. The study concluded that the accountability for committing these frauds could not go beyond those who directly participated in the deviant practice, exceptionally reaching members of the party that institutionally contributed to distorting the affirmative policy. Based on these findings, we understand that the TSEs decision incurs the malpractice of the democratic and constitutional pillars and may lead to autophagy of affirmative politics.

Keywords: Gender quota. Non-viable candidacies ("candidaturas laranja"). Orange candidates. Objective liability. Electoral sanctioning right.

Artigo recebido em 12 out. 2020 e aprovado em 21 out. 2020. 


\section{Introdução}

Dos mais diversos setores da sociedade em que a desigualdade de gênero é flagrante, sem dúvida, a esfera política se destaca como das mais proeminentes e resistentes. É sabido que, historicamente, esse lugar não só não foi concebido para as mulheres, como o pacto social pela modernidade garantiu que a autodeterminação política fosse (e permanecesse) garantida somente aos homens brancos e proprietários (PATEMAN, 1993, p. 15-37).

Para fazer frente a este machismo histórico e estrutural, tanto das instituições em geral como, e em especial, dos partidos políticos, grandes responsáveis pela dificuldade da mulher em ascender aos cargos eletivos, desde a década de 90, algumas ações afirmativas têm sido efetivadas no País. Das mais proeminentes, a que determinou que ao menos 30\% das candidaturas de cada partido fossem preenchidas por mulheres, o que ficou conhecida como a "cota de gênero" (art. 10, \ 3oㅡㄹ da Lei 9.504/97 - Lei das Eleições -LE-, com a redação dada pela Lei n.12.034/2009).

Entretanto, apesar do avanço na promoção formal da igualdade de gênero, alcançar a concretude desta ação afirmativa não está sendo tarefa fácil. Isso porque, desde que foi estabelecida, constatou-se uma série de "fraudes" na sua execução, de forma que as mulheres ainda não estão, devidamente, ocupando esse espaço, tampouco essa política afirmativa tem conseguido alcançar o fim a que se propõe: ampliação das mulheres ocupando cargos eletivos. Tais situações começaram a ser rotuladas de "candidaturas laranja", em que as mulheres preenchiam formalmente a respectiva cota, mas, na prática, não eram candidatas.

E é nesse contexto que surge a necessidade de intervenção da Justiça Eleitoral, a fim de resguardar a legitimidade e normalidade do pleito. Em tese, a averiguação da fraude deveria ocorrer quando do registro do Demonstrativo de Regularidade de Atos Partidários (DRAP), momento em que os partidos precisam, dentre outros requisitos, comprovar o preenchimento da cota de gênero. Entretanto, é muito difícil constatar esse tipo de irregularidade nesta fase, justamente porque ela praticamente só é possível de ser identificada no curso da campanha (SILVEIRA, 2019, p. 173).

Disso decorrem duas problemáticas: não há previsão legal de um outro momento específico em que se poderia constatar e investigar a fraude à cota de gênero, nem no que precisamente ela consiste, o que a caracteriza e qual o instrumento processual que melhor permite a sua aferição. 
Para além das questões processuais, ou mesmo substantivas (configuração de fraude ou abuso), outras questões de suma importância devem ser verificadas, a análise das consequências da configuração do ilícito (sanções cominadas), notadamente quanto à extensão da cassação dos mandatos em relação àqueles (homens e mulheres eleitos) que não concorreram com a realização da fraude, tampouco tinham conhecimento dela.

Em relação às eleições de 2016, após ruidosas decisões de Cortes Regionais que determinaram a cassação de chapas inteiras pelo reconhecimento da fraude à cota de gênero, a questão chegou enfim ao Tribunal Superior Eleitoral (TSE), no julgamento do Recurso Especial Eleitoral n. 19392, do Estado do Piauí, de relatoria do ministro Jorge Mussi. O julgamento deste caso foi emblemático, não somente por se constituir em um leading case sobre a matéria, mas pela riqueza do debate travado no âmbito do Tribunal.

Nesse contexto, este estudo visa se debruçar sobre as fórmulas de imputação da responsabilidade eleitoral e a consequente extensão das sanções aplicadas na apuração das fraudes às cotas de gênero.

A pesquisa adota como método de investigação o "método dedutivo", em face do qual a análise sobre a extensão de aplicação da sanção pela fraude à cota de gênero se insere no âmbito do direito eleitoral sancionador e, como tal, exige a estrita observância do devido processo legal, que se expressa, entre outras garantias, na necessidade de demonstração de dolo e/ou culpa e de nexo de causalidade para imputação de responsabilização. Ou seja, na impossibilidade, considerando-se tratar de imposição de sanção que restringe direitos políticos fundamentais e a própria soberania popular, de uso das fórmulas de responsabilização objetiva.

$\mathrm{Na}$ primeira seção, é feito um breve levantamento dos primeiros mecanismos de ação afirmativa voltados à inclusão das mulheres na política até a promulgação da Lei n. 12.034/2009, com especial ênfase na criação da exigência de destinação de 30\% das candidaturas às mulheres (art. 10, \3은 da Lei 9.504/97). Além disso, é feita uma apresentação geral sobre as características gerais que passaram a caracterizar as "fraudes" às cotas, tendo em vista a ausência de regulamentação legal nesse sentido.

Na seção seguinte, é realizado um detalhamento dos principais argumentos exarados no julgamento do REspe n. 19392 do TSE, em especial no que diz respeito às fórmulas de responsabilização eleitoral e a delimitação dos beneficiários das fraudes, que levou a Corte Superior a concluir pela aplicação da cassação dos mandatos de toda a chapa. 
$\mathrm{Na}$ última seção, é especificamente analisada a legitimidade das decisões proferidas e, tendo em vista o seu enquadramento como direito eleitoral sancionador, defende-se que as mesmas, com o sentido que lhes é atribuído neste artigo, afrontam ao devido processo legal.

Nas conclusões, enfrenta-se e se desconstrói o argumento de que a referida decisão promove a ação afirmativa em prol da maior participação das mulheres na política. Ainda são sintetizadas as conclusões parciais discutidas no trabalho, chamando a atenção para o fato de que, em se tratando de direito sancionador, deve-se assegurar aos sancionados (e, em especial, às sancionadas) um conjunto de garantias de defesa e de limites para imposição da responsabilidade eleitoral, tendo em vista que jamais se pode perder de vista que a declaração de fraude à cota de gênero (e a cassação dos mandatos respectivos) representa uma faceta do exercício do jus puniendi estatal.

\section{2 “Evolução" histórica da reserva de cotas de gênero para candidaturas}

As políticas de ação afirmativa para fomentar a participação política da mulher ganharam lugar na agenda nacional após a IV Conferência Internacional sobre a Mulher, de 1995, realizada pela Organização das Nações Unidas, em Pequim. Nesta Conferência paradigmática, todos os países que lá se reuniram, entre os quais o Brasil, comprometeram-se a adotar mecanismos destinados ao fomento da participação das mulheres nos órgãos governamentais dos países signatários (ONU, 1995).

Prontamente, houve uma mobilização por parte de parlamentares e ativistas brasileiras para que algumas ações fossem implementadas a tempo das eleições de 1996. Isso culminou com a aprovação da Lei n. 9.100, em 29 de setembro de 1995, que instituiu a cota mínima de 20\% para candidaturas femininas aos partidos políticos (PIMENTEL FILHO; RODRIGUES, 2017, p. 131-133; MELO, 2018).

Apesar da grande novidade que a lei impôs, ela encerrou duas sutis artimanhas que acabaram por reduzir o impacto concreto dessa norma, quais sejam: (a) o número de candidaturas passou de 100\% do número de vagas a preencher no parlamento para $120 \%$ (o que, na prática, não exigiu que os partidos "reduzissem" as candidaturas masculinas naquele pleito); e (b) o limite a ser preenchido por candidatas mulheres (20\%) tinha como referência o número máximo de candidaturas a serem registradas abstrata- 
mente, ou seja, se houvessem 10 cargos em disputa, como o partido poderia inscrever 12 candidatos, era obrigado a deixar 3 vagas reservadas para mulheres (já que 3 vagas é o número inteiro que corresponde a 20\% de 12 vagas). Ou seja, o partido poderia lançar 9 homens e nenhuma candidata mulher e, ainda assim, estaria respeitando as vagas "reservadas" às mulheres, nos termos da lei. É por esta razão que se referem à norma como se ela tivesse um caráter opcional (RODRIGUES, 2017, p. 31).

Em 30 de setembro de 1997, com a promulgação da lei que deveria ser a Lei Geral das Eleições (n. 9.504), o percentual foi ampliado para $30 \%$ (art. 10, \ $3^{\circ}$ ), tendo sido igualmente ampliado para $150 \%$ o número de candidatos que poderiam ser registrados por partidos políticos ou coligações (NORONHA, 2016, p. 64; SILVA; SANTOS, 2015, p. 439). Portanto, o mesmo "problema" resultante da política de reserva de candidaturas, acabou por reduzir o estímulo legal ao preenchimento de vagas por candidatas mulheres, dada a sua "facultatividade".

Em essência, portanto, não houve diferença significativa entre as referidas normas, tendo em vista que apenas houve, na prática, um aumento do percentual de $120 \%$ para $150 \%$ do número de candidatos, bem como continuou não existindo quaisquer sanções para seu descumprimento (NORONHA, 2016, p. 65; SILVA; SANTOS, 2015, p. 439-440).

Somente com a edição da Lei n. 12.034/2009 é que o ordenamento jurídico brasileiro passa a adotar mecanismos um pouco mais incisivos destinados à promoção da participação feminina na política mediante, dentre eles destaca-se a inclusão de um comando obrigatório aos partidos para que inscrevessem efetivamente um "percentual mínimo de candidaturas femininas" nos pleitos eleitorais (alteração da redação do $\int 3^{\circ}$ do art. 10 da Lei das Eleições, quando a expressão "deverá reservar" foi substituída pela expressão "preencherá2", o que atribuiu caráter cogente à norma, eliminando de vez quaisquer dúvidas acerca de sua obrigatoriedade (NORONHA, 2016, p. 24).

\footnotetext{
${ }^{1}$ Art. 10, \ 30: "Do número de vagas resultante das regras previstas neste artigo, cada partido ou coligação deverá reservar o mínimo de 30\% (trinta por cento) e o máximo de $70 \%$ (setenta por cento) para candidaturas de cada sexo".

2 "Do número de vagas resultante das regras previstas neste artigo, cada partido ou coligação preencherá o mínimo de 30\% (trinta por cento) e o máximo de $70 \%$ (setenta por cento) para candidaturas de cada sexo".
} 
No que diz respeito à modificação literal relacionada à cota dos $30 \%$, isso motivou também alteração na jurisprudência sobre o tema pelo TSE, que passou a considerar a necessidade de observância do número de candidatos apresentados pelo partido/coligação para fins do cálculo do percentual mínimo exigido por gênero (SILVA; SANTOS, 2015, p. 440).

Apesar da exigência de $30 \%$ de vagas por gênero, garantida pela Lei 12.034/2009, os resultados dessa política afirmativa se mostraram pouco significativos, conforme se apontou de forma introdutória. Apesar do pequeno avanço na representatividade, à medida em que a exigência legal passou a ser cobrada e as sanções pelo descumprimento aplicadas pela Justiça Eleitoral, o que se verificou foi um efeito reverso: uma série de artifícios utilizados pelos partidos políticos para se eximirem da obrigação ou de cumpri-la apenas formalmente, conforme aponta pesquisa das professoras Malu Gatto, da University College London, e Kristin Wyllie, da James Madison University (PASSARINHO, 2019) ${ }^{3}$.

Segundo o levantamento, houve um aumento no uso de candidaturas femininas fictícias entre os anos de 2008 e 2018, culminando com $35 \%$ de "laranjas" nas últimas eleições, como resposta à mudança na lei de cotas, ao contrário do que se esperava da ação afirmativa (PASSARINHO, 2019). Fato impulsionado muito provavelmente pela destinação de verbas específicas para campanhas femininas, a partir do exclusivo financiamento público de campanhas estabelecido em 2018 (SANTANO; TAILANI; BASTOS JR, 2019).

Os partidos e/ou coligações acabam por lançar candidatas apenas para cumprir o mínimo legal, dando-lhes pouco ou nenhum apoio e tornando suas candidaturas inviáveis, quando não são efetivamente "figu-

\footnotetext{
${ }^{3}$ Não foi possível acessar diretamente o estudo realizado, tendo em vista que a reportagem não fez a devida referência, tampouco indicou link de acesso ao estudo. As demais reportagens encontradas só replicaram a original desenvolvida pela BBC. No currículo pessoal da pesquisadora Malu Gatto também não consta referência ao estudo (Disponível em: $<$ https://www.malugatto.com/publications $>$.), somente menção à reportagem aqui citada (https://www.malugatto.com/media), tampouco na de Kristin Wylie (Disponível em: <https://www.jmu.edu/polisci/downloadable_materials/Wylie_CV.pdf $>$ ). Encontrou-se somente um estudo desenvolvido por esta, junto a diferentes coautores, em que também chegou à conclusão do aumento no uso de candidaturas laranja à medida de implementação das cotas, mas considerando dados de até 2016. (Disponível em: https://www.scielo.br/scielo. php?script=sci_arttext\&pid=S0104-62762019000100001). Acredita-se, diante disso, que o levantamento tenha sido feito realmente a pedido da BBC para fins jornalísticos.
} 
rantes" (RAMOS, 2017, p. 07). Essas modalidades se encaixam no que se cunhou chamar de "candidaturas femininas fictícias", que em geral podem se configurar a partir de alguns fatores como a não realização de atos de campanha, não recebimento de doações e/ou nem de votos, sequer o próprio (RAMOS, 2017, p. 07).

Pode-se dizer que candidatas "laranja", para fins eleitorais, são as candidaturas lançadas somente para preencher a cota de gênero instituída pela Lei das Eleições e como meio para a aplicação de recursos públicos de financiamento de campanha em benefício de outros candidatos [masculinos] do partido e/ou coligação (NASCIMENTO; MOREIRA, 2019, p. 170).

Segundo decidiu o TSE, no REspe 149, também do Estado do Piauí, a fraude à cota de gênero é passível de ser perpetrada, portanto, não somente pela simulação de candidaturas de mulheres que sequer sabiam dessa condição, como também pela indicação meramente formal dessas aos cargos proporcionais (ANDRADE NETO; GRESTA; SANTOS, 2018, p. 240).

Tendo em vista a falta de previsão legal que estabelecesse a fraude à cota de gênero como um tipo específico de ilícito eleitoral, bem como, e consequentemente, quais atos a caracterizariam, a solução foi dada, segundo já apontado, pela via jurisprudencial. O que acarreta, dentre outros fatores, numa atividade ex post facto dos tribunais, quando estabelecem, diante dos casos concretos, o que caracteriza ou não a fraude à cota de gênero, considerando-se essa como uma modalidade de fraude ou de abuso de poder lato sensu. Tal característica é comum a essas categorias de ilícitos eleitorais, em especial às condutas relacionadas ao abuso de poder, o que foi já alvo de maiores aprofundamentos em outras ocasiões ${ }^{4}$. Como se defende neste trabalho, a aplicação automática de fórmulas de responsabilização objetiva, empregadas para a configuração das fraudes às cotas de gênero, são ainda mais graves nesse contexto, porquanto sua definição e alcance sequer se encontravam jurisprudencialmente delimitadas anteriormente às eleições de 2016.

\footnotetext{
${ }^{4}$ A problemática ao redor do tratamento dos ilícitos eleitorais como ilícitos civis, com a consequente adoção de uma tipicidade aberta e amplo poder na mão dos julgadores para defini-los, foram trabalhados de forma mais ampla anteriormente em sede de Monografia (CUNHA, 2019, p. 48-58), bem como de forma específica no artigo A natureza sancionatória dos ilícitos eleitorais não criminais, destes autores, apresentado no XXVIII Encontro Nacional do CONPEDI (CUNHA, BASTOS JR, 2019).
} 
Diante disso, e do surgimento desses novos fatos jurídicos relacionados à realização dos pleitos eleitorais, as lacunas foram sendo colmatadas pelos tribunais regionais eleitorais do País, até que sobreveio a decisão do Tribunal Superior Eleitoral, objeto de análise deste artigo.

\section{Trajetória judicial para fixação da extensão das sanções por fraude à cota de gênero e o REspe 193-92 do Tribunal Superior Eleitoral}

Os primeiros casos ajuizados relacionados a fraudes às cotas de gênero, conforme já mencionado preliminarmente, ocorreram no Estado do Piauí 5 . Apesar de o mérito das questões não ter sido analisado na ocasião, foi graças a esses casos que o TSE fixou, pela primeira vez em 2015, no já citado REspe 149, que tais situações poderiam ser caracterizadas como fraudes e apuradas mediante AIME 6 . Posteriormente, em 2016, no REspe 243-42, proveniente mais uma vez do Piauí, o TSE entendeu que essas situações poderiam se enquadrar como formas de abuso de poder, podendo ser apuradas também mediante à Ação de Investigação Judicial Eleitoral (AIJE) para suprir a necessidade de se apurar as condutas entre o registro do DRAP e a diplomação dos eleitos ${ }^{7}$.

\footnotetext{
${ }^{5}$ RCED n. 404/PI e AIME n.149/PI.

${ }^{6}$ RECURSO ESPECIAL. AÇÃO DE IMPUGNAÇÃO DE MANDATO ELETIVO. CORRUPÇÃO. FRAUDE. COEFICIENTE DE GÊNERO. [...] 2. O conceito da fraude, para fins de cabimento da ação de impugnação de mandato eletivo (art. 14, \10, da Constituição Federal), é aberto e pode englobar todas as situações em que a normalidade das eleições e a legitimidade do mandato eletivo são afetadas por ações fraudulentas, inclusive nos casos de fraude à lei. A inadmissão da AIME, na espécie, acarretaria violação ao direito de ação e à inafastabilidade da jurisdição. Recurso especial provido. (Recurso Especial Eleitoral n. 149, acórdão, relator: min. Henrique Neves da Silva. Publicação: DJE - Diário de justiça eletrônico, 21 out. 2015. p. 25-26).

${ }^{7}$ RECURSO ESPECIAL. AÇÃO DE INVESTIGAÇÃO JUDICIAL ELEITORAL. FRAUDE. PERCENTUAIS DE GÊNERO. CAPTAÇÃO ILÍCITA DE SUFRÁGIO.

[...] 4. É possível verificar, por meio da ação de investigação judicial eleitoral, se o partido político efetivamente respeita a normalidade das eleições prevista no ordenamento jurídico - tanto no momento do registro como no curso das campanhas eleitorais, no que tange à efetiva observância da regra prevista no art. $10, \int 3^{\circ}$, da Lei das Eleições - ou se há o lançamento de candidaturas apenas para que se preencha, em fraude à lei, o número mínimo de vagas previsto para cada gênero, sem o efetivo desenvolvimento das candidaturas. [...]. (Recurso Especial Eleitoral n. 24342. Acórdão. Relator: min. Henrique Neves da Silva. Diário de justiça eletrônico, Tomo 196, 11 out. 2016. p. 65-66).
} 
Ultrapassadas as delimitações processuais e conceituais, não sem as respectivas (e devidas) críticas e a persistência das problemáticas decorrentes do entendimento firmado nesses aspectos ${ }^{8}$, a partir das eleições de 2016, uma série de ações foram ajuizadas perante os diferentes órgãos da Justiça Eleitoral brasileira.

A partir do momento em que o TSE chancelou a possibilidade de aferição de fraude à cota de gênero (quer seja através de AIMEs, quer seja por meio de AIJEs), a controvérsia (doutrinária e jurisprudencial) passou a gravitar sobre dois aspectos centrais, quais sejam: os critérios para a configuração da fraude e o alcance das decisões judiciais que a reconhecem.

Entre as Cortes Regionais que declararam a existência da fraude à cota de gênero (Tribunal Regional Eleitoral de São Paulo, de Santa Catarina, do Rio Grande do Sul e do Piauí9), quanto às consequências deste reconhecimento, as decisões foram uníssonas: deveria ser determinada a cassação de todos os integrantes da chapa (mandatários ou não), como decorrência lógica da desconstituição do próprio DRAP, sendo sancionado pela cominação da inelegibilidade somente àqueles que concorreram ou consentiram dolosamente com a fraude.

O caso, enfim, chegou ao TSE. Nas proximidades do julgamento do paradigmático REspe 193-92, de pronto formou-se uma corrente majoritária apoiando a tese de "cassação de todo mundo senão essa ação afirmativa de defesa das mulheres não terá efeito nenhum e distorcerá o cálculo de representação paritária” (SILVEIRA, 2019, p. 164).

O REspe em questão analisou em conjunto três recursos referentes às eleições proporcionais de 2016, do Estado do Piauí, e a decisão se deu em torno de quatro aspectos, que podem ser resumidos da seguinte forma:

a) o não reconhecimento de litisconsórcio passivo necessário na demanda para inclusão dos dirigentes partidários, pelo fato de não haver provas de que tinham conhecimento ou anuíram com as fraudes ${ }^{10}$;

\footnotetext{
${ }^{8}$ Dentre os posicionamentos da doutrina, destaca-se o excelente artigo escrito por João Andrade Neto, Roberta Gresta e Polianna Santos (2018) sobre o assunto.

${ }^{9}$ RECURSO n. 37054/SP; RDJE n. 234/SC; RE n. 49585/RS.

10 “[...] PRELIMINAR. LITISCONSÓRCIO PASSIVO NECESSÁRIO. DIRIGENTES PARTIDÁRIOS. SÚMULA 24/TSE. REJEIÇÃO.3. O TRE/PI assentou inexistir prova de que os presidentes das agremiações tinham conhecimento da fraude, tampouco que anuíram ou atuaram de modo direto ou implícito para sua consecução, sendo incabível citá-los para integrar a lide como litisconsortes passivos necessários. Concluir de forma diversa esbarra no óbice da Súmula 24/TSE [...] ” (REspe n. 19392).
} 
b) a exigência de provas robustas para caracterização da fraude ${ }^{11}$;

c) a impossibilidade de cassação dos candidatos ao pleito majoritário, por não se demonstrar que a higidez do pleito foi afetada ${ }^{12}$; e

d) a delimitação das consequências jurídicas das fraudes, que implica na cassação de toda a chapa, considerando-se todos os candidatos beneficiários, sem a necessidade de comprovação de quaisquer aspectos subjetivos, que devem ser averiguados apenas para a imposição da sanção de inelegibilidade ${ }^{13}$.

Atendo-se ao objeto maior deste estudo, far-se-á algumas delimitações adicionais acerca das consequências jurídicas do cometimento da fraude à cota de gênero e a forma de imputação da responsabilização eleitoral.

Os argumentos centrais da tese vencedora, adotada pelos ministros Jorge Mussi, Tarcísio Vieira, Roberto Barroso e Rosa Weber, foram os seguintes: a) os ilícitos do art. 22, inc. XIV da Lei Complementar 64/90, dos quais

11 “[... TEMA DE FUNDO. FRAUDE. COTA DE GÊNERO. ART. 10, \ 3ํㅗ DA LEI 9.504/97. ROBUSTEZ. GRAVIDADE. AFRONTA. GARANTIA FUNDAMENTAL. ISONOMIA. HOMENS E MULHERES. ART. 5, I, DA CF/88.4. A fraude na cota de gênero de candidaturas representa afronta à isonomia entre homens e mulheres que o legislador pretendeu assegurar no art. 10, \ 3을 da Lei 9.504/97 - a partir dos ditames constitucionais relativos à igualdade, ao pluralismo político, à cidadania e à dignidade da pessoa humana - e a prova de sua ocorrência deve ser robusta e levar em conta a soma das circunstâncias fáticas do caso, o que se demonstrou na espécie. 5. A extrema semelhança dos registros nas contas de campanha de cinco candidatas - tipos de despesa, valores, data de emissão das notas e até mesmo a sequência numérica destas - denota claros indícios de maquiagem contábil. A essa circunstância, de caráter indiciário, somam-se diversos elementos específicos [...]” (REspe n. 19392).

12 “[...] CASSAÇÃO. DIPLOMAS. PREFEITA E VICE-PREFEITO. AUSÊNCIA. REPERCUSSÃO. SÚMULA 24/TSE.16. Não se vislumbra de que forma a fraude nas candidaturas proporcionais teria comprometido a higidez do pleito majoritário, direta ou indiretamente, ou mesmo de que seria de responsabilidade dos candidatos aos cargos de prefeito e vice-prefeito. Conclusão diversa esbarra na Súmula 24/TSE.CONCLUSÃO. MANUTENÇÃO. PERDA. REGISTROS. VEREADORES. EXTENSÃO. INELEGIBILIDADE. IMPROCEDÊNCIA. CHAPA MAJORITÁRIA.[...]” (REspe n. 19392).

13 “[...] CASSAÇÃO. DIPLOMAS. PREFEITA E VICE-PREFEITO. AUSÊNCIA. REPERCUSSÃO. SÚMULA 24/TSE.16. Não se vislumbra de que forma a fraude nas candidaturas proporcionais teria comprometido a higidez do pleito majoritário, direta ou indiretamente, ou mesmo de que seria de responsabilidade dos candidatos aos cargos de prefeito e vice-prefeito. Conclusão diversa esbarra na Súmula 24/TSE.CONCLUSÃO. MANUTENÇÃO. PERDA. REGISTROS. VEREADORES. EXTENSÃO. INELEGIBILIDADE. IMPROCEDÊNCIA. CHAPA MAJORITÁRIA.[...]” (REspe n. 19392). 
fariam parte as fraudes às cotas de gênero, dispensam quaisquer análises de participação ou anuência, bem como de elementos subjetivos, acarretando na cassação de todos os beneficiados; b) aqueles que cometeram, participaram, anuíram ou tiveram conhecimento da fraude, além de terem seus mandatos cassados, também são declarados inelegíveis; e c) o que está em jogo são os bens jurídicos não só de igualdade na disputa, mas também de legitimidade, normalidade e lisura do pleito, que seriam afetados pela fraude.

Ainda, merece destaque a defesa de que a não cassação de toda chapa, mas somente as candidatas fraudulentas, estimularia os partidos e as coligações a usar o mesmo artifício em outras eleições, tendo em vista o reaproveitamento dos votos em favor da legenda, nos termos do art. 175, \ $4^{\circ}$ do Código Eleitoral (CE) (TSE, 2019b, p. 37 e 126). Entretanto, ao mesmo tempo, reconhece-se que essas candidatas poucos ou nenhum voto teriam, o que também, segundo alegado pelo relator, estimularia os partidos a usar o artifício, pelo mesmo argumento de que se fossem vir a ser cassadas, não haveria grandes prejuízos para os cálculos de quociente eleitoral (TSE, 2019b, p. 80). Ou seja, por esse aspecto, não subsiste lógica que valide o raciocínio adotado.

Divergindo da maioria, inicialmente o ministro Edson Fachin pontua que a fórmula de responsabilidade objetiva adotada para os casos de abuso de poder do art. 22, XVI, da LC 64/90 se justifica porque impactam na formação da vontade do eleitor e acarretam um desequilíbrio da disputa, o que não ocorre com as cotas de gênero (TSE, 2019b, p. 71).

Discorre que a fraude à cota de gênero não guarda relação com a isonomia entre as candidaturas, pois tem objetivo de fomentar a participação feminina na política, não afetando, portanto, a igualdade da disputa (TSE, 2019b, p. 72). Dessa forma, defende que aqueles que não anuíram nem participaram da fraude à cota de gênero não podem ser equiparados àqueles que são favorecidos pelo abuso praticado por terceiro, nos moldes previstos (TSE, 2019b, p. 72). Ou seja, nas hipóteses tradicionais de abuso, o próprio jogo político está viciado pelo ilícito, desnivelando os concorrentes, enquanto que na fraude à cota de gênero a violação se dá a uma política afirmativa (TSE, 2019b, p. 72). Por essa especificidade, ressalta que a apuração dessa deve ter um regime próprio, que não afete o próprio equilíbrio de forças na disputa e a soberania popular e respeite a importância dos direitos políticos (TSE, 2019b, p. 72-73). Como solução, o ministro defende a aplicação das sanções somente àqueles diretamente envolvidos na fraude (TSE, 2019b, p. 74). 
Apesar de seguir o relator em alguns aspectos, no que diz respeito à imposição e extensão das sanções, o ministro $\mathrm{Og}$ Fernandes acompanha $\mathrm{o}$ ministro Fachin e defende que, diferente dos casos tradicionais de abuso de poder, com impacto na legitimidade e normalidade do pleito, nas fraudes às cotas a regra ocorre o inverso: há um desconhecimento quanto à fraude por parte dos demais candidatos, tendo em vista que essas costumam ocorrer no mais absoluto sigilo (TSE, 2019b, p.104 e105). E ainda: que, em verdade, os demais candidatos possuem é prejuízo com tais candidaturas, tendo em vista a importância dos votos a serem conquistados numa eleição proporcional (TSE, 2019b, p. 106).

Conclui por dizer que o mero benefício de participar da legenda/ coligação não se subsume ao do art. 22, inc. XIV da LC 64/90, devendo ser responsabilizado apenas aquele que tiver conhecimento e/ou anuência do ilícito praticado, chamando a atenção para o fato de que adotar tal fórmula seria decretar o instituto da responsabilização sem previsão legal (TSE, 2019b, p. 106 e 107). Ou seja, nos casos de apuração de fraude à cota de gênero não é possível a presunção do conhecimento dos demais candidatos, dada a substancial diferença quanto à natureza do benefício obtido (TSE, 2019b, p. 107).

$\mathrm{Na}$ esteira desse entendimento, também o ministro Sérgio Banhos salienta que as decisões relacionadas às fraudes não podem desconsiderar o elemento subjetivo dos acusados, reforçando que isso, considerando toda complexidade de formação de coligações e divisão de atribuições aos envolvidos nas eleições, fere diretamente a soberania popular e a própria normalidade do pleito (TSE, 2019b, p. 145). Chama a atenção para a necessidade de proporcionalidade e equilíbrio na atuação da Justiça Eleitoral, para que essa não promova distorções, inclusive com a cassação de mandatárias eleitas, de forma que a aplicação de sanções deve ser correspondente ao limite de responsabilidade ou anuência (TSE, 2019b, p. 146).

Por fim, de importante destaque, o ministro ressalta acertadamente que se a fraude fosse descoberta durante o processo de registro ou mesmo durante a campanha, haveria a possibilidade de redução das candidaturas de outro gênero ou de reajustes, podendo a coligação ser preservada (TSE, 2019b, p. 147), demonstrando mais uma vez a desproporcionalidade da cassação por completo da chapa.

Entretanto, apesar dessa decisão proferida pelo TSE, o debate está longe de ser considerado superado. Tramita perante o Supremo Tribunal Federal (STF) a Ação Direta de Inconstitucionalidade (ADI) 6338, propos- 
ta pelo partido Solidariedade, com pedido cautelar, para que se interprete o art. 10 \3ำ da Lei 9.504/97 conforme a constituição, ou que se declare sua inconstitucionalidade sem redução de texto, quando combinado com o art. 22, XVI, da Lei Complementar 64/90, nos casos de abuso de poder decorrentes das fraudes à cota de gênero.

Em linhas gerais, pleiteia-se nessa ADI que não haja responsabilização objetiva das chapas, devendo a sanção ser restringida à agremiação partidária da candidata "laranja" e àqueles que comprovadamente tiverem contribuído ou consentido com o abuso. Dentre os principais argumentos levantados está justamente a teoria do impacto desproporcional da decisão do TSE no REspe 192-32 sobre o objetivo da política afirmativa, que é o aumento da participação feminina na política, notadamente pela cassação de mandatos de mulheres legitimamente eleitas por conta do entendimento de que se deve punir toda coligação, bem como pelo ônus de terem que fiscalizar a escolha dos dirigentes partidários, que são os principais responsáveis pela definição de candidatos e candidatas e são os que assinam a regularidade do DRAP.

Muito embora a partir das eleições de 2020 não haja mais coligações para as eleições proporcionais, os precedentes expostos acima estão aptos a influenciar diversos julgamentos ainda pendentes nos tribunais eleitorais do país. Desse modo, considerando-se que a desconstituição do DRAP por fraude à cota de gênero e o correlato sancionamento (destituição dos mandatos e cominação de inelegibilidade) são exercidos como desdobramento do jus puniendi estatal, passar-se-á no próximo tópico a refletir sobre a questão pela perspectiva do direito eleitoral sancionador, a fim de fornecer subsídios que contribuam para encontrar uma saída para essa questão, que seja compatível com a ordem constitucional e convencional vigentes.

\section{A cassação da coligação partidária por violação ao art. $10, \mathbb{S} 3^{\circ}$, da Lei 9.504/97 na perspectiva do direito eleitoral sancionador}

A questão que está aqui a se enfrentar é a imputação de sanções àqueles ou àquelas das quais não se pode identificar ou extrair elementos que comprovem a participação direta, indireta e/ou anuência com a fraude cometida. Exclui-se dessa análise, por óbvio, a imputação de sanções a todas e todos que contribuíram com o ilícito, correligionários partidários ou 
coligados, pois comprovada a ação ou omissão, dolosa ou culposa, que contribuiu para a fraude às cotas, justifica-se a responsabilização. O problema reside na fórmula que o TSE adotou para imputar as sanções por fraudes às cotas de gênero para além desses parâmetros, que excluiu a análise de quaisquer elementos subjetivos para aferição das condutas.

Longe de ser uma inovação do tribunal, a forma de processamento desses ilícitos, aos quais a fraude à cota de gênero foi acrescida, segue uma lógica civilista, sendo tratados, portanto, como se meros ilícitos civis o fossem, apesar de sua incontestável natureza sancionatória (CUNHA, 2019, p. 53; CUNHA; BASTOS JR, 2019a, p. 263). Aplica-se, diante disso, em muitas situações, o regime de distribuição do ônus da prova e dos elementos probatórios associados às ações voltadas a reparações de danos na esfera privada, de forma desarrazoada, desproporcional e incompatível com a natureza desses institutos, segundo já vem sendo alertado ${ }^{14}$.

Essa ênfase atribuída à natureza "cível" contribui para que, em nome da preservação da legitimidade da disputa eleitoral, se promovam restrições ao exercício do devido processo legal que se mostram absolutamente inaceitáveis com a ordem constitucional vigente e com o sistema internacional de proteção dos direitos humanos (CUNHA, 2019, p. 49; CUNHA; BASTOS JR, 2019a, p. 263).

Isso fica demonstrado quando se analisa as fórmulas adotadas para a responsabilização eleitoral, brevemente demonstradas para apuração das fraudes às cotas de gênero, em que a análise dos elementos subjetivos foi simplesmente descartada.

A situação se torna ainda mais grave quando essas fórmulas são aplicadas aos supostos beneficiários, quando não há sequer a demonstração de nexo de causalidade entre a conduta e o resultado danoso sobre o bem jurídico tutelado pela norma eleitoral, que autorizaria a responsabilização do candidato (CUNHA, 2019, p. 55; CUNHA; BASTOS JR, 2019a, p. 268). Ou seja, admite-se cassar um mandato legitimamente conferido nas urnas, em razão da prática de atos cometidos por terceiros, sem qualquer prova sobre a participação na (ou conhecimento sobre a) ilicitude pela candidata (SALGADO; VALIATI; BERNADELLI, 2016, p. 337).

Adota-se nessas situações, em verdade, uma teoria do risco integral para imputação eleitoral, que torna a candidata, mesmo que sem qualquer conhecimento prévio ou participação, responsável por todos os atos

${ }^{14}$ Vide nota de rodapé n. 4 e os estudos de Silveira (2017), (2019), (2019a). 
praticados em sua campanha eleitoral (SILVEIRA, 2017, p. 37). As condutas de abuso de poder não dispensam, expressamente, o nexo de causalidade ou o elemento subjetivo para responsabilização do beneficiário do ato ilícito, limitando-se a dizer que será a eles imposta a perda de seus mandatos (SILVEIRA, 2017, p. 39).

Esse aspecto ganha maior relevância com a temática de fundo deste estudo. Esse “dever" de zelar pelos atos de todos que atuam na campanha eleitoral impõe um dever sobremaneira excessivo, especialmente sobre as candidatas, que já enfrentam uma série de dificuldades e obstáculos a mais do que os homens ao terem que lidar com todas as formas de machismo estrutural dos partidos políticos e da própria sociedade perante a qual precisam realizar suas campanhas.

Além disso, as mulheres possuem pouco ou nenhum poder decisório na liderança e direção dos partidos, sendo necessária recente intervenção judicial para que a exigência das cotas de gênero fosse estendida para as eleições dos órgãos partidários ${ }^{15}$, de forma que em hipóteses muito remotas teriam condições de saber ou mesmo anuir com quaisquer fraudes. Uma decisão dessa, tomada supostamente para protegê-las, se torna mais um peso que as mulheres passam a carregar no já árduo caminho que percorrem até o cargo eletivo.

Diante disso, há uma clara ofensa aos princípios do devido processo legal, do contraditório e da ampla defesa, sem base normativa específica nem para as formas "tradicionais" de abuso de poder e/ou fraude e menos ainda para as fraudes às cotas. $\mathrm{O}$ uso dessa teoria excepcionalíssima segue, conforme já alertado por Silveira (2017, p. 39 e 40), sem quaisquer justificativas por parte do TSE, o qual reitera apenas que "a cassação busca restabelecer a legitimidade do processo eleitoral, ainda que o ilícito tenha sido praticado por terceiro".

No caso das cotas de gênero, segundo demonstrado, sequer essa legitimidade é atingida, pois o que a norma protege é a ação afirmativa em prol da materialização do princípio da igualdade para promover as mulheres na política (SILVEIRA, 2019, p. 172).

Nesse contexto generalizado de desrespeito ao devido processo legal que vigora na seara eleitoral, é imprescindível reafirmar o efeito que

${ }^{15}$ Disponível em: <http://www.tse.jus.br/imprensa/noticias-tse/2020/Maio/tse-entende-ser-aplicavel-reserva-de-genero-para-mulheres-nas-eleicoes-para-orgaos-partidarios $>$.

Resenha Eleitoral (Florianópolis), v. 24, n. 1, p. 57-84, 2020 
decisões como essas acarretam no cerceamento de um direito fundamental de tamanha importância, que é o próprio direito de sufrágio (CUNHA, 2019, p. 57; CUNHA; BASTOS JR, 2019a, p. 270). Por tais motivos, decisões que impliquem em inelegibilidade, cassação de registro ou diploma deveriam ser revestidas de maiores proteções e respeitar limites estritos, devendo o Poder Judiciário intervir em casos extremos, visando garantir a livre formação e manifestação do voto, mas nunca para alterar a vontade do eleitor (SALGADO; VALIATTI; BERNADELLI, 2016, p. 345 e 346).

Conforme demonstrado, pesou mais na balança da Justiça Eleitoral a suposta proteção de legitimidade do pleito, com a tomada de uma decisão que não observou as regras do devido processo legal, culminando com sanções de tamanha gravidade e em detrimento da própria política afirmativa em favor das mulheres, pois duas delas, legitimamente eleitas, também tiveram os mandatos cassados ${ }^{16}$. Ou seja, um absoluto contrassenso, uma autofagia da ação afirmativa e um desincentivo à participação das mulheres (SILVEIRA, 2019, p. 165).

Inclusive, esse foi um argumento central levantado na ADI 6338 pelos peticionários, o qual foi rebatido pela Associação Visibilidade Feminina que, como amicus curiae no processo, alegou que não havia sido apontado nenhum caso em que mulheres legitimamente eleitas teriam sido afetadas pela extensão das punições a toda chapa (2020, p. 15). A realidade, conforme apontado, milita em sentido contrário.

Defende-se neste trabalho que, como quaisquer outras sanções aplicadas pela Justiça Eleitoral às agremiações partidárias ou candidatos (as) em função do descumprimento de regras legais, as punições decorrentes das fraudes às cotas de gênero devem igualmente ser compreendidas como exercício do jus puniendi estatal e, como tal, ensejam a aplicação daquilo que, em outra oportunidade, se convencionou chamar como direito eleitoral sancionador (CUNHA, 2019, p. 59; CUNHA; BASTOS JR, 2019, p. 204) ${ }^{17} 18$.

${ }^{16}$ Fátima Caetano, filiada ao PTC, e Ariana Rosa, filiada ao partido PMN, tiveram seus mandatos cassados por conta da identificação de fraudes às cotas de gênero em outros partidos que compuseram as coligações de que fizeram parte, Compromisso com Valença I e II, respectivamente, nas eleições de 2016, na cidade de Valença/PI.

${ }^{17}$ Frederico Franco Alvim (2019, p.135) também se utiliza desta expressão para classificar o ramo ao qual pertencem todos os ilícitos eleitorais, sem, contudo, se debruçar sobre o conceito.

${ }^{18}$ Rodrigo Lopez Zílio, em recente obra, também se utiliza dessa expressão para defender a individualização do Direito Eleitoral como ciência autônoma, de status constitucional, 
O direito eleitoral sancionador pode ser qualificado como um ramo do contencioso eleitoral que visa à apuração de uma conduta antijurídica em face da qual o Estado aplica uma sanção que pode consistir na imposição de uma obrigação de conduta (facere ou non facere), na cominação de sanção pecuniária, na imputação de uma medida restritiva de direitos (entre as quais se destacam as inelegibilidades) e/ou, ainda, na cassação de um registro ou de um mandato resultante do exercício de sufrágio eleitoral (CUNHA, 2019, p. 50; CUNHA; BASTOS JR, 2019, p. 205).

Como todo processo de natureza sancionatória, o contencioso eleitoral voltado à apuração da imputação de condutas qualificadas como ilícitos eleitorais exige a estrita observância de garantias processuais ínsitas ao devido processo legal, sob pena de grave malversação de um dos pilares da ordem constitucional vigente, inerente à regra de ouro do Estado de Direito (CUNHA, 2019, p. 50; CUNHA; BASTOS JR, 2019, p. 205).

Por derradeiro, quanto mais severas são as sanções passíveis de serem aplicadas aos imputados, tanto mais efetivas devem ser as garantias de defesa que lhes devem ser asseguradas (CUNHA, 2019, p. 50; CUNHA; BASTOS JR, 2019, p. 205). Isso porque tais ilícitos, em que pese não estarem previstos como crimes, em muitas situações preveem sanções mais severas que muitas sanções cominadas aos ilícitos penais eleitorais, assim como, em diversos contextos, protegem bens jurídicos semelhantes em seu grau de importância ao adequado funcionamento das regras do jogo democrático (CUNHA; BASTOS JR, 2019, p. 205).

Diante disso, defende-se como premissa teórica que não há (ou não deveria haver) diferenças substanciais no que diz respeito ao regime de produção probatória, de ampla defesa e contraditório, do direito a um recurso eficaz, à segurança jurídica, à exigência de elemento subjetivo (dolo e/ou culpa) e demais garantias inerentes ao devido processo legal para imputação de sanções.

Ao qualificar que a aplicação de uma sanção (no caso, a cassação de mandato legitimamente conferido pelas urnas por conta da identificação de

com ênfase na defesa de um regime próprio de responsabilização eleitoral independente da esfera penal ou administrativa (2020, p. 77-93). Partindo dos pressupostos de que os direitos políticos são direitos fundamentais, da contramajoritariedade das decisões da Justiça Eleitoral, da problemática ao redor do amplo poder instrutório conferido pelo art. 23 da Lei de Inelegibilidades, propõe alguns critérios de conformação democrática às decisões eleitorais no contexto do direito sancionador eleitoral. Entretanto, ainda o faz por uma perspectiva cível e não sancionatória. 
fraude às cotas de gênero estabelecidas pelo art. 10, \ $3^{\circ}$, da Lei 9.504/97), se insere no âmbito do direito eleitoral sancionador, se está a reclamar que deva ser aplicado aos candidatos e candidatas um conjunto de garantias processuais próprias inerentes a esse ramo do direito ${ }^{19}$.

$\mathrm{Na}$ falta de estudos mais aprofundados acerca da manifestação do jus puniendi estatal direcionados à esfera eleitoral entre os autores nacionais ${ }^{20}$, recorreu-se a autores mexicanos que, provocados pela necessidade de diferenciação entre o contencioso administrativo e judicial eleitoral que ocorre naquela jurisdição, já se ocupam em construir identidade própria a esse ramo (ÁLVAREZ GONZALEZ, 2009; VÁZQUEZ RANGEL, 2012; ROSET'TE SOLÍS, 2012).

Nesse contexto, entre as garantias do devido processo apontadas por tais autores, defende-se que para caracterização dos ilícitos eleitorais, dos quais fazem parte as fraudes às cotas de gênero, deve-se exigir de forma imperiosa a identificação de elemento subjetivo (VAZQUEZ RANGEL, 2012, p. 54; ALVARÉZ GONZALEZ, 2009, p. 41 e 42). Defende-se, ainda, que o dolo deve ganhar o papel predominante, relegando a culpa (sempre culpa grave) para hipóteses mais restritas, conforme a gravidade das pe-

19 Também no estudo ampliado realizado em sede de Monografia, a individualização e caracterização do direito eleitoral sancionador, bem como algumas premissas teóricas para a construção de um modelo processual compatível, foram desenvolvidas de forma mais aprofundada (CUNHA, 2019, p. 67-74).

${ }^{20}$ É digno de nota que Fernando Gaspar Neisser, ao se debruçar sobre um modelo intermediário de imputação subjetiva para as improbidades administrativas, situado entre o Direito Penal e o Direito Civil, construído a partir da ideia de sanções civis punitivas, denominado middleground, considerou que este seria aplicável às ações eleitorais, por justamente reconhecê-las como sancionatórias (2018, p. 151 - nota de rodapé n. 497). Na tese, defendeu ainda que a gravidade das sanções (aptas a atingirem os direitos políticos fundamentais) concorre para que o dolo deva ser considerado como elemento imprescindível para a configuração do ato de improbidade administrativa, de forma que somente a reserva legal poderia instituir exceções a serem interpretadas restritivamente, dispensando-se dessa forma quaisquer mecanismos de responsabilização objetiva ou presunção de culpa (NEISSER, 2018, p. 205-252). Paulo Henrique dos Santos Lucon (2016), em estudo sobre a conduta de captação ilícita de sufrágio do art. 41-A da Lei das Eleições, também defende que a imputação dos ilícitos eleitorais não pode prescindir do elemento dolo. É bem verdade que o faz de forma específica à conduta de captação ilícita de sufrágio, cujo dolo específico está previsto na LE (art. 41-A $\left.\int 1^{\circ}\right)$, mas sua fundamentação se dá ao redor do fato de que uma cassação de mandato ou registro não pode se dar por mera probabilidade, devendo se basear em elementos que permitam ao julgador firmar sua convicção além de qualquer dúvida razoável e somente com presunção de dolo, raciocínio que poderia se aplicar, sem sombra de dúvidas, aos demais ilícitos eleitorais "não-criminais" (LUCON, 2016, p. 309 e 310). 
nas previstas pelos ilícitos (CUNHA, 2019, p. 67; CUNHA; BASTOS JR, 2019a, p. 278).

Entretanto, ressalta-se que foge ao escopo deste trabalho definir qual modalidade de dolo ou culpa deveriam ser consideradas para responsabilização eleitoral, restringindo-se à defesa imprescindível de que a cassação de registro/mandato e a sanção de inelegibilidade jamais poderiam decorrer de mecanismos de responsabilização objetiva e, mais ainda, que dispensem o ônus à acusação de demonstração da existência de nexo de causalidade entre os imputados e a conduta tida por ilícita (CUNHA, 2019, p. 67; CUNHA; BASTOS JR, 2019a, p. 278).

Diante disso, com todo acautelamento às teses contrárias, não há fundamento na ordem constitucional brasileira que dê sustentação a fórmulas de responsabilização que dispensem a imputação subjetiva em quaisquer ramos do direito sancionador. Nesse sentido, entendemos que não se pode também presumir quaisquer dolo e/ou culpa de todos os integrantes da chapa por conta do registro de um DRAP que tenha alguma candidatura que, ao longo do processo eleitoral, tenha se revelado fictícia, conforme defendeu também a Associação Visibilidade Feminina (2020, p. 17). Inclusive, como bem delimitado por ela, o registro das candidaturas é ato partidário, e não dos candidatos e candidatas de toda coligação ${ }^{21} 22$.

21 “O momento do abuso ocorre, portanto, no ato do registro, momento anterior à própria campanha eleitoral e às eleições, de forma que os mandatos que acabam sendo perdidos pela cassação do registro nunca possuíram condições legais de existência. Candidatos já entraram na disputa de forma ilegal, e se torna impossível validar tanto a candidatura quanto a eleição de todos que integram a lista fraudada. Portanto, não há que se falar em responsabilidade objetiva, uma vez que o registro das candidaturas cumprindo todas as regras eleitorais é ato partidário e, ao se constatar a fraude no demonstrativo de regularidade, quaisquer cargos conquistados por integrantes são cassados porque o próprio nascimento daquelas candidaturas foi irregular, e, portanto, nunca deveriam ter sido deferidas." (VISIBILIDADE FEMININA, 2020. p. 17).

${ }^{22}$ Nesse sentido decidiu o TSE: ELEIÇÕES 2012. PRESTAÇÃO DE CONTAS DE CANDIDATO. VEREADOR. [...] IMPOSSIBILIDADE DE CONTAMINAÇÃO AUTOMÁTICA DAS CONTAS DO CANDIDATO. HIPÓTESE ODIOSA DE RESPONSABILIDADE OBJETIVA NA SEARA ELEITORAL. [...] 7. A contaminação automática das contas do candidato, ante a desaprovação das contas de sua agremiação por auferir recursos provenientes de fonte vedada pela legislação eleitoral, encerra indevida e odiosa hipótese de responsabilidade objetiva na seara eleitoral, na medida em que a rejeição de suas contas independerá de qualquer exame do dolo daquele a quem fora repassada a verba. [...] (Recurso Especial Eleitoral n. 85911/MG).

Resenha Eleitoral (Florianópolis), v. 24, n. 1, p. 57-84, 2020 
Permitir a responsabilização de toda chapa cria uma fórmula de cassação perversa, que afronta não só a própria ação afirmativa, como todo um conjunto de dispositivos constitucionais e legais (SILVEIRA, 2019, p. 175-177).

Com isso, este estudo vem somar à tese de que a imputação das fraudes às cotas de gênero não pode prescindir de identificação de elemento subjetivo para caracterização das condutas, nem de nexo de causalidade entre o suposto responsável e o dano ao bem jurídico tutelado (SILVEIRA, 2019, p. 174; SANTANO; TAILANI; BASTOS JR, 2019). Tampouco que se pode validar a defesa de que se está protegendo a legitimidade do pleito com essas medidas e a própria política de ação afirmativa, tendo em vista que a decisão proferida sobrecarrega ainda mais as mulheres em campanha.

Essa limitação para imputação da responsabilidade, considerando o dever de promoção de uma política afirmativa tão importante que está em jogo, só poderia se tornar flexível por uma concepção geral de participação indireta e de benefício da fraude nos limites da agremiação partidária (SANTANO; TAILANI; BASTOS JR, 2019). Ou seja, seria até certa medida razoável imputar, para além dos diretamente envolvidos na fraude, isto é, ao respectivo partido, as sanções aplicadas por conta do uso de candidatas fictícias, tendo em vista que é a agremiação a responsável por referendar as respectivas candidaturas (SANTANO; TAILANI; BASTOS JR, 2019).

Seguindo a mesma linha de raciocínio desses autores, ultrapassar a agremiação partidária feriria não só a individualização da responsabilidade pela fraude, conforme já bem explorado, como ignoraria o fato de que no momento em que as convenções partidárias são realizadas não há anuência da futura coligação sobre quaisquer decisões individuais dos partidos.

Porém, ressalta-se que essa responsabilização tampouco pode se dar de uma forma objetiva. Considerando ser o partido político uma pessoa jurídica, é preciso pensar de que forma essa responsabilidade se daria, especialmente pela proibição de responsabilização penal da agremiação e da aproximação entre ilícitos eleitorais e penais já brevemente apontada. $\mathrm{Na}$ falta de estudos nacionais sobre a temática, recorre-se à sugestão do já citado autor mexicano Osíris Vazquez Rangel que, em estudo sobre a adaptação da teoria do delito aos ilícitos eleitorais mexicanos, discorre sobre a responsabilização dos partidos políticos também depender da demonstração dos elementos de dolo e/ou culpa (2012, p. 53). 
Para o autor, o partido incorrerá em dolo quando cometer uma ação ou omissão com objetivo de praticar uma conduta típica eleitoral ou o descumprimento de uma norma (VAZQUEZ RANGEL, 2012, p. 53). Esse conceito de dolo substituiria o "conhecer e o querer" do direito penal para pessoas físicas, quando, por exemplo, o partido se organiza internamente para cometer o ilícito eleitoral ${ }^{23}$.

Já para a responsabilização por culpa, esta se daria a partir do que se conhece como erro de tipo vencível no âmbito penal ${ }^{24}$, quando o partido não teve intenção de incorrer no ilícito eleitoral, mas não se organizou e agiu diligentemente a fim de evitar que a legislação fosse descumprida pelas candidatas (e por aqueles diretamente vinculados), quando podia fazê-lo, bem como por não agir prudentemente na fiscalização, o que legitimaria sua responsabilização ${ }^{25}$.

23 "Es dolosa la concreta acción u omisión realizada con base en la autonomía y libertad de organización de los partidos políticos, coaliciones o personas, que tiene como objeto la obtención del resultado típico electoral, o el incumplimiento de la expectativa normativa. Este concepto de dolo sustituye al "conocer y querer" del derecho penal para las personas físicas, y se sintetiza en que hay dolo cuando el partido político o coalición se organiza internamente para incumplir con la expectativa normativa electoral; por ejemplo, cuando decide que no haya controles, concentra el manejo de dinero en una sola persona o decide no bacer revisiones al uso de recursos" (VAZQUEZ RANGEL, 2012, p. 53).

${ }^{24}$ Nas lições de Cezar Roberto Bittencourt: "Erro de tipo é o que recai sobre circunstância que constitui elemento essencial do tipo. É a falsa percepção da realidade sobre um elemento do crime. É a ignorância ou a falsa representação de qualquer dos elementos constitutivos do tipo penal. [...] Por exemplo, no crime de calúnia, o agente imputa falsamente a alguém a autoria de um fato definido como crime que, sinceramente, acredita tenha sido praticado. Falta-lhe o conhecimento da elementar típica 'falsamente', uma condição do tipo. [...] O erro de tipo invencível (inevitável), também referido como erro de tipo essencial, sempre exclui o dolo, permitindo, quando for o caso (tratando-se de erro evitável), a punição pelo crime culposo, uma vez que a culpabilidade permanece intacta" (2015, p. 511-512). O erro de tipo está previsto no art. 20 do Código Penal, segundo o qual 'O erro sobre elemento constitutivo do tipo legal de crime exclui o dolo, mas permite a punição por crime culposo, se previsto em lei."

25 "En otro orden de ideas, es posible que cuando la organización tiene el objetivo de cumplir con las expectativas normativas, pero éstas no se realicen por la ejecución defectuosa y la comisión de errores; en este supuesto, la organización generada con base en la autonomía y libertad de auto-organización, debido a falta de mecanismos adecuados para el cumplimiento de las expectativas normativas, tiene como consecuencia el resultado típico electoral (incumplimiento de la expectativa normativa). La producción del resultado típico electoral por una organización que partía de una serie de errores, da lugar a que decaiga el dolo, pero al ser obligación de las asociaciones políticas el mantener una organización que garantice el cumplimiento de las expectativas normativas, subsiste un minimo de injusto, de tal manera que dicho error, al ser normativamente exigible su evitación, es sancionable. Esta figura es conocida en el derecho penal como error de tipo 
Ou seja, diferentemente de uma responsabilização objetiva ou mesmo uma presunção de culpa ${ }^{26}$, o partido realmente tem participação direta no registro das candidaturas e tem o dever de se articular para o cumprimento da ação afirmativa, o que implica necessariamente no uso de candidatas reais. Se não agiu diligentemente nesse sentido, ofendeu o bem jurídico protegido pela política de cotas, ainda que de forma culposa, pois não buscou materialmente cumprir com a legislação e, com isso, frustrou o objetivo de aumento da participação política da mulher.

A partir desses parâmetros, no caso em questão, apurado dolo e/ ou culpa do partido político, ocorreria o indeferimento parcial do DRAP somente em relação a este, por não ter preenchido o requisito exigido pelo $\int 3^{\circ}$ do art. 10 da LE (notadamente por ter lançado candidatas fictícias), atingindo todas e todos os candidatos (as) vinculados (as) ao partido. Dessa forma, preservar-se-ia o restante da coligação, alternativa que já foi utilizada pelo TSE quando reconheceu que a demonstração de fraude na convenção de um dos partidos integrantes de coligação não tem o condão de contaminar a coligação em sua totalidade, bastando, no caso, a exclusão da agremiação ${ }^{27}$.

vencible, y se sanciona como los hechos culposos. El "error de tipo electoral", se presenta cuando el partido político o coalición desarrolla un supuesto sancionable (tipo electoral) porque ha fallado en cuanto a organizarse de manera adecuada para evitar los resultados probibidos, ha actuado con falta de cuidado (esto es la culpa o imprudencia en el derecho penal). De esta manera, al decir que un partido político es competente para responder por el incumplimiento de las expectativas normativas, se le reconoce como persona jurídica, y porque puede organizarse libremente, debe mantenerse dentro de los riesgos permitidos o responder por los resultados que produzca. Cuando una asociación politica se organiza de tal manera que se adecua a un supuesto sancionable previsto en la normatividad electoral, desarrolla el tipo electoral (o supuesto de becho electoral y no penal). tope, se configuran con los lineamientos mencionados" (VAZQUEZ RANGEL, 2012, p. 53-54).

${ }^{26}$ Nesse sentido, o TSE, no Recurso Especial Eleitoral n. 181, reformou uma decisão do Tribunal Regional Eleitoral do Rio Grande do Sul, na qual este concluiu que a origem de recursos da campanha do caso em questão eram ilícitos somente porque não aceitaram a origem declarada dos respectivos recursos no processo de prestação de contas. Dessa forma, estabeleceu que não se pode presumir a culpa do candidato e condená-lo, pois isso configuraria "flagrante desrespeito ao devido processo legal e à soberania popular” (REspe n. 181/MG).

27 “1. A eventual ocorrência de fraude na convenção de um ou mais partidos integrantes de coligação não acarreta, necessariamente, o indeferimento do registro da coligação, mas a exclusão dos partidos cujas convenções tenham sido consideradas inválidas. 2. Excluídos da coligação, os partidos em relação aos quais foram constatadas irregularidades nas atas das convenções, defere-se o registro da coligação e, por consequência, dos candidatos por ela escolhidos.3. Recurso especial provido.” (Recurso Especial Eleitoral n. 2204. Acórdão. Relator: min. Henrique Neves da Silva. Diário de justiça eletrônico, Tomo 85, p. 51). 
Diante do exposto, de uma forma sintetizada, pode-se elencar as premissas defendidas neste estudo, no que diz respeito à forma de aplicação e extensão das sanções por fraudes às cotas de gênero sob a perspectiva do direito eleitoral sancionador, da seguinte maneira:

a) não é possível a imputação de responsabilidade eleitoral de forma objetiva, sendo necessária a existência de dolo ou culpa para caracterização do ilícito;

b) para além das e dos diretamente envolvidos na fraude, o partido político ao qual se vincula a candidatura fictícia pode (ou deve?) ser responsabilizado por dolo e/ou culpa, podendo ser excluído da coligação; e

c) é preciso verificar o nexo de causalidade entre a conduta e o dano causado ao bem jurídico protegido pelas cotas, qual seja o aumento da participação politica feminina.

\section{Conclusão}

A partir de todo exposto, demonstra-se a necessidade de se refletir sobre os limites do exercício do poder sancionatório do Estado, expresso por meio da Justiça Eleitoral no contexto de um direito eleitoral sancionador. A ansiedade por punir aqueles que efetivamente tentam burlar políticas de ação afirmativa tão importantes, num meio já tão excludente, machista e antidemocrático como o cenário das eleições e dos próprios partidos políticos, não pode ensejar que se desrespeite as regras do devido processo legal.

Não se quer, com isso, diminuir a importância da preservação das conquistas até aqui obtidas, tampouco da necessidade de resistência frente aos ataques sistemáticos a elas. $\mathrm{O}$ ambiente com o qual a mulher se depara na política é um ambiente hostil e cercado de empecilhos que visam mantê-la afastada, mas se entende que o combate ao machismo estrutural tão presente em todos os setores da sociedade, e mais ainda nas instituições políticas, não pode se dar com o esvaziamento das garantias do devido processo legal. E, mais ainda, com o aumento do já problemático protagonismo do Poder Judiciário neste cenário.

É preciso levar a sério as políticas de ação afirmativa em prol da participação da mulher na política. Porém, decisões como a exarada pelo TSE no REspe 193-92, longe de promovê-las, causam, na verdade, além de todas as injustiças flagrantes, uma sobrecarga às mulheres que se colocam nas disputas eleitorais, que passam a ter que superar todas as barreiras que 
já lhe são impostas para ocupar este espaço, como ter que monitorar os atos do partido e de toda coligação ao qual ele se vincula e que muito provavelmente nenhum poder de decisão tiveram sobre a aliança. Com isso, o que se consegue é desencorajá-las e afastá-las ainda mais deste espaço de poder, indo de encontro ao propósito da ação afirmativa que se busca defender com tais medidas.

Espera-se, enfim, que este estudo sirva para fomentar um debate mais cuidadoso sobre o precedente estabelecido no REspe 193-92 pelo TSE, tanto pela doutrina e, em especial pelos tribunais eleitorais do país, que podem ter a chance de rever o posicionamento em seus próximos julgamentos e evitar que se acentue ainda mais a falta de representatividade democrática.

\section{Referências}

ÁLVAREZ GONZÁLEZ, Juan Manoel. Alguns principios del derecho penal sustativo aplicables al derecho sancionador electoral. p. 17-46. In: El ilicíto y su castigo: reflexiones sobre la cadena perpetua, la pena de muerte y laidea de sanción en el derecho / David Cienfuegos Salgado - México : Editora Laguna : Fundación Académica Guerrerense : Universidad Autónoma de Guerrero, Maestría en Derecho Público, Universidad Autónoma de Sinaloa, Unidad de Posgrado en Derecho, 2009. 348 p.

ALVIM, Frederico Franco. Abuso de poder nas competições eleitorais. Curitiba: Juruá, 2019. 408 p.

ANDRADE NETO, João; GRESTA, Roberta Maia; SANTOS Polianna Pereira dos. Fraude à cota de gênero como fraude à lei: os problemas conceituais e procedimentais decorrentes do combate às candidaturas femininas fictícias. In: FUX, Luiz; PEREIRA, Luiz Fernando Casagrande; AGRA, Walber de Moura (Coord.); PECCININ, Luiz Eduardo (Org.). Abuso de poder e perda de mandato. Belo Horizonte: Fórum, 2018. p. 239-281. (Tratado de Direito Eleitoral, v. 7.) ISBN 978-85-450-0502-5.

ASSOCIAÇÃO VISIBILIDADE FEMININA. Memorial de Amicus Curiae na Ação Direta de Inconstitucionalidade 6338 do Supremo Tribunal Federal. Disponível em: < http://redir.stf.jus.br/estfvisualizadorpub/jsp/ consultarprocessoeletronico/ConsultarProcessoEletronico.jsf?seqobjetoincidente $=5879329>$. 
BRASIL. Tribunal Superior Eleitoral. Recurso Especial Eleitoral n. 2204. Acórdão. Relator: min. Henrique Neves da Silva. Diário de justiça eletrônico, 09 maio 2014.

. Tribunal Superior Eleitoral. Recurso Especial Eleitoral n. 149. Acordão. Relator: min. Henrique Neves da Silva. Diário de justiça eletrônico, 21 out. 2015.

. Tribunal Superior Eleitoral. Recurso Especial Eleitoral n. 181. Acórdão. Relator min. Gilmar Ferreira Mendes. Diário de justiça eletrônico, 29 abril 2015.

. Tribunal Superior Eleitoral. Recurso Especial Eleitoral n. 24342. Acórdão. Relator: min. Henrique Neves da Silva. Diário de justiça eletrônico, 11 out. 2016.

. Tribunal Superior Eleitoral. Recurso Especial Eleitoral n. 19392. Acórdão Relator: min. Jorge Mussi. Diário de justiça eletrônico, 04 out. 2019 (b).

CUNHA, Amanda Guimarães da. De player político a árbitro no direito sancionador eleitoral: o resgate do dever de imparcialidade do julgador a partir das garantias convencionais. 2019. 135fls. Monografia - Universidade do Vale do Itajaí, SC.

CUNHA, Amanda Guimarães da; BASTOS JUNIOR, Luiz Magno Pinto.

O Fomento à participação política e o controle do jus puniendi estatal: a Lei n. 13.831/2019 sob a perspectiva do direito eleitoral sancionador. Revista Estudos Eleitorais: Tribunal Regional Eleitoral de Santa Catarina, 2019. v. 23, n.1, p. 187-212.

. A Natureza jurídica sancionatória dos ilícitos eleitorais "não criminais". In: MORAES FILHO, José Filomeno de; TORRES, Vivian de Almeida Gregori (Org.). Teorias da Democracia, direitos Políticos e Filosofia do Estado. 1.ed. Florianópolis: CONPEDI, 2019ª v. 1, p. 262-281.

DIAS, Willian Silva; VIEIRA, Murilo Braz. Os custos com as campanhas eleitorais à luz da reforma eleitoral de 2015 (Lei n. 13.165/2015). Revista Estudos Eleitorais: Tribunal Regional Eleitoral de Santa Catarina, 2017. v. 12, n. 3. LUCON, Paulo Henrique dos Santos. "Compra de votos", direito sancionador e ônus de prova. In: TAVARES, André Ramos; AGRA, Walber de Moura; PEREIRA, Luiz Fernando (Coord.). O direito eleitoral e o novo Código de Processo Civil. Belo Horizonte: Fórum, 2016. p. 307-316. 
MELO, Hilda Pereira de. A política de cotas para as mulheres no Brasil: importância e desafios para avançar! 13 de setembro de 2018. Disponível em: $<$ http://www.generonumero.media/a-politica-de-cotas-para-as-mulheres-no-brasil-importancia-e-desafios-para-avancar/>.

NASCIMENTO, Camila Teixeira do; MOREIRA, Diogo Rais Rodrigues. Igualdade de gênero nas eleições: a fraude no processo eleitoral através de candidatas laranjas. Revista Estudos Eleitorais: Tribunal Regional Eleitoral de Santa Catarina, 2019. v. 23, n.1, p. 165-185.

NEISSER, Fernando Gaspar. A responsabilidade subjetiva na improbidade administrativa: um debate pela perspectiva penal. 2018. 313fls. Tese de Doutorado - Faculdade de Direito da Universidade de São Paulo, São Paulo, SP.

NORONHA, Fernanda Benini Kiehl. Diretrizes e desafios da participação feminina na política brasileira: uma análise comparada a partir de Argentina e México. 2016. 105 fls. Monografia - Universidade Federal do Paraná, PR.

ORGANIZAÇÃO DAS NAÇÕES UNIDAS. Declaração e plataforma de ação da IV Conferência mundial sobre a mulher. 1995. Disponível em: <http://www.onumulheres.org.br/wp-content/uploads/2014/02/declaracao_pequim.pdf $>$.

PASSARINHO, Nathalia. Candidatas laranjas: pesquisa inédita mostra quais partidos usaram mais mulheres para burlar cotas em 2018. Divulgada em: 08 de março de 2019. Disponível em: < https://www.bbc.com/portuguese/brasil-47446723>.

PATEMAN, Carole. O contrato sexual. Trad. Marta Avancini. Rio de janeiro: Paz Terra, 1993. 345p.

PIMENTEL FILHO, José Ernesto; RODRIGUES, Mariana Ramos. A política legislativa e a proteção à participação política da mulher: uma interpretação histórica de processos legislativos. Revista A Barriguda. Campina Grande, 7 [], p. 127-149, jan.-abr. 2017.

ROSETTE SOLÍS, Bertha Leticia. Naturaleza jurídica del derecho electoral sancionador: algunas consideraciones en torno al Libro Quinto del Código de Instituciones y Procedimientos Electorales del Distrito FederalTribunal Electoral del Distrito Federal. Mexico, 2012. Disponível em: https:/ /www.tecdmx.org. $\mathrm{mx} /$ files/326/publicaciones/varias/naturaleza_juridica.pdf

VAZQUEZ RANGEL, Osíris. Derecho sancionador electoral y principio de legalidade. Electio Revista Especializada Electoral. Num. 2, Jun-Dic 2012. Primera edición, Diciembre 2012. p. 37-60. Disponível em: https:/ /www. tecdmx.org.mx/files/326/publicaciones/electio/02_electio.pdf 
RAMOS, Luciana de Oliveira. Os tribunais eleitorais e as candidaturas femininas fictícias. 2017. Disponível em: <http://bibliotecadigital.tse.jus.br/ xmlui/bitstream/ handle/bdtse/5347/2017_ramos_tribunais_eleitorais_candidaturas.pdf? sequence $=1$ \&is Allowed $=\mathrm{y}>$.

RODRIGUES, Ricardo José Pereira. A evolução da política de cota de gênero na legislação eleitoral e partidária e a sub-representação feminina no parlamento brasileiro. Revista Eletrônica Direito e Política, Programa de Pós-Graduação Stricto Sensu em Ciência Jurídica da Univali, ISSN 1980-7791, Itajaí, v.12, n.1, 1º quadrimestre de 2017. Disponível em: < https://www.univali.br/direitoepolitica>.

ROSETTTE SOLÍS, Bertha Leticia. Naturaleza jurídica del derecho electoral sancionador: algunas consideraciones en torno al Libro Quinto del Código de Instituciones y Procedimientos Electorales del Distrito Federal Tribunal Electoral del Distrito Federal. Mexico, 2012. Disponível em: <https://www.tecdmx. org.mx/files/326/publicaciones/varias/naturaleza_juridica.pdf $>$.

SALGADO, Eneida Desiree; VALIATI, Thiago Priess; BERNADELLI, Paula. O livre convencimento do juiz eleitoral versus a fundamentação analítica exigida pelo novo Código de Processo Civil. In: TAVARES, André Ramos; AGRA, Walber de Moura; PEREIRA, Luiz Fernando (Coord.). O direito eleitoral e o novo Código de Processo Civil. Belo Horizonte: Fórum, 2016. p. 335-358.

SANTANO, Ana Cláudia; COSTA, Tailane Cristina; BASTOS JUNIOR, Luiz Magno Pinto. Um debate sobre as consequências das fraudes em candidaturas femininas. Revista Consultor Jurídico, 27 de maio de 2019. Disponível em: $<$ https://www.conjur.com.br/2019-mai-27/opiniao-consequencias-fraudes-candidaturas-femininas $>$.

SILVA, Adriana Campos; SANTOS, Polianna Pereira dos. Participação política feminina e a regulamentação legal das cotas de gênero no Brasil: breve análise das eleições havidas entre 1990 e 2014. In: SILVA, Adriana Campos; OLIVEIRA, Armando Albuquerque; MORAES FILHO, José Filomeno de. (Org.). Teorias da Democracia e Direitos Políticos. Florianópolis: CONPEDI, 2015. p. 427-448.

SILVEIRA, Marilda de Paula. Conduta Vedada e Abuso de Poder: como lidar com o nexo de causalidade em ato praticado por terceiro. Revista Resenha Eleitoral (Florianópolis), v. 21, n. 1, p. 29-42, nov. 2017. Disponível em: $<$ https://www.tre- sc.jus.br/site/fileadmin/arquivos/ejesc/documentos/Condutas_Vedadas_e_abuso_do_poder_politico_para_EJE_SC.pdf > . 
As consequências da identificação de candidaturas fictícias: cassação das eleitas e desincentivos à representatividade feminina na política. Revista Estudos Eleitorais: Tribunal Regional Eleitoral de Santa Catarina, 2019. v. 23, n.2, p. 161-186.

VAZQUEZ RANGEL, Osíris. Derecho sancionador electoral y principio de legalidade. Electio Revista Especializada del Tribunal Electoral del Distrito Federal. n. 2, jun.-dic., 2012. Primera edición, Diciembre 2012. p. 37-60. Disponível em: <https://www.tecdmx.org.mx/files/326/publicaciones/electio/02_electio.pdf>.

WYLIE, Kristin; SANTOS, Pedro dos; MARCELINO, Daniel. Extreme non-viable candidates and quota maneuvering in Brazilian legislative elections. Opinião Publica, Campinas, v. 25, n. 1, p. 1-28, Abril, 2019. Disponível em: https://www.scielo.br/scielo.php?script=sci_arttext\&pid=S0104-62762019000100001 http://dx.doi.org/10.1590/1807019120192511.

ZILIO, Rodrigo Lopez. Decisão de cassação de mandato: um método de reestruturação. Salvador: Editora JusPodivm, 2019. 304 p.

Amanda Guimarães da Cunha - Especialista em Direito Eleitoral pelo Instituto para o Desenvolvimento Democrático (IDDE) e em Ciências Penais pela Anhanguera-Uniderp. Bacharela em Direito pela Universidade do Vale do Itajaí (Univali). Membro Pesquisadora do Observatório do Sistema Interamericano de Direitos Humanos (Univali) nas áreas de direitos humanos, direito eleitoral e processual eleitoral, direito penal e processual penal e temáticas de gênero. E-mail: amandagdacunha@gmail.com.

Luiz Magno Pinto Bastos Júnior - Pós-Doutor pelo Centro de Direitos Humanos e Pluralismo Jurídico da Universidade McGill (Montreal, Canadá). Doutor e Mestre em Direito pela Universidade Federal de Santa Catarina (UFSC). Graduado em Direito pela Universidade Federal do Pará (UFPA). Professor do Programa de Mestrado e Doutorado em Ciência Jurídica da Universidade do Vale do Itajaí (Univali) das disciplinas de Direito Constitucional, Direito Eleitoral e Direitos Humanos no curso de Graduação em Direito. Advogado militante nas áreas de direito eleitoral e direito administrativo (sócio do Escritório Menezes Niebuhr Advogados Associados). Membro fundador da Academia Brasileira de Direito Eleitoral e Político (Abradep) e Academia Catarinense de Direito Eleitoral (Acade). Coordenador do Observatório do Sistema Interamericano de Direitos Humanos (Univali). E-mail: lmagno@univali.br / lmagno@mnadvocacia.com.br. 